
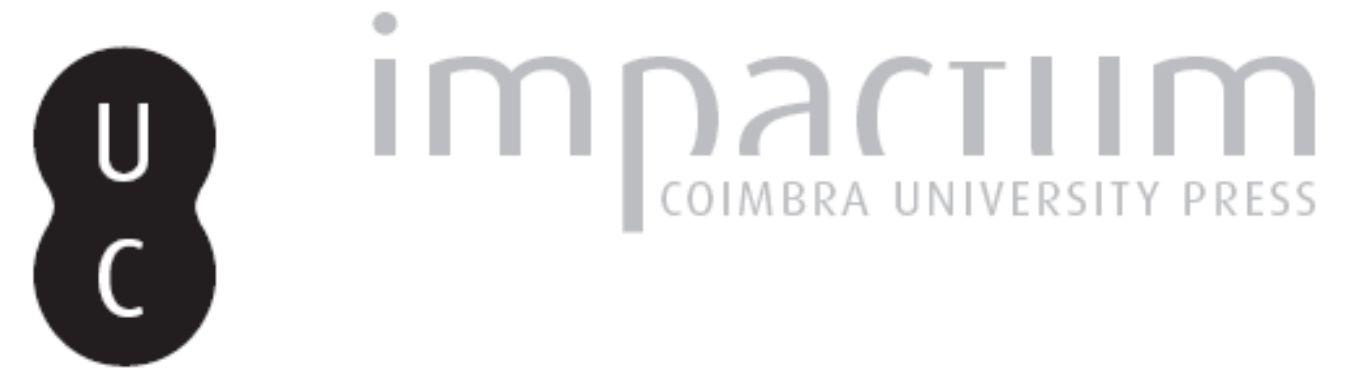

\title{
Florestas e grandes incêndios florestais no mundo
}

Autor(es): $\quad$ Rebelo, Fernando

Publicado por: Associação Portuguesa de Riscos, Prevenção e Segurança

URL persistente:

URI:http://hdl.handle.net/10316.2/40160

DOI:

DOI:https://doi.org/10.14195/1647-7723_3_1

Accessed : $\quad$ 26-Apr-2023 12:53:40

A navegação consulta e descarregamento dos títulos inseridos nas Bibliotecas Digitais UC Digitalis, UC Pombalina e UC Impactum, pressupõem a aceitação plena e sem reservas dos Termos e Condições de Uso destas Bibliotecas Digitais, disponíveis em https://digitalis.uc.pt/pt-pt/termos.

Conforme exposto nos referidos Termos e Condições de Uso, o descarregamento de títulos de acesso restrito requer uma licença válida de autorização devendo o utilizador aceder ao(s) documento(s) a partir de um endereço de IP da instituição detentora da supramencionada licença.

Ao utilizador é apenas permitido o descarregamento para uso pessoal, pelo que o emprego do(s) título(s) descarregado(s) para outro fim, designadamente comercial, carece de autorização do respetivo autor ou editor da obra.

Na medida em que todas as obras da UC Digitalis se encontram protegidas pelo Código do Direito de Autor e Direitos Conexos e demais legislação aplicável, toda a cópia, parcial ou total, deste documento, nos casos em que é legalmente admitida, deverá conter ou fazer-se acompanhar por este aviso.

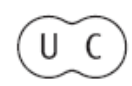




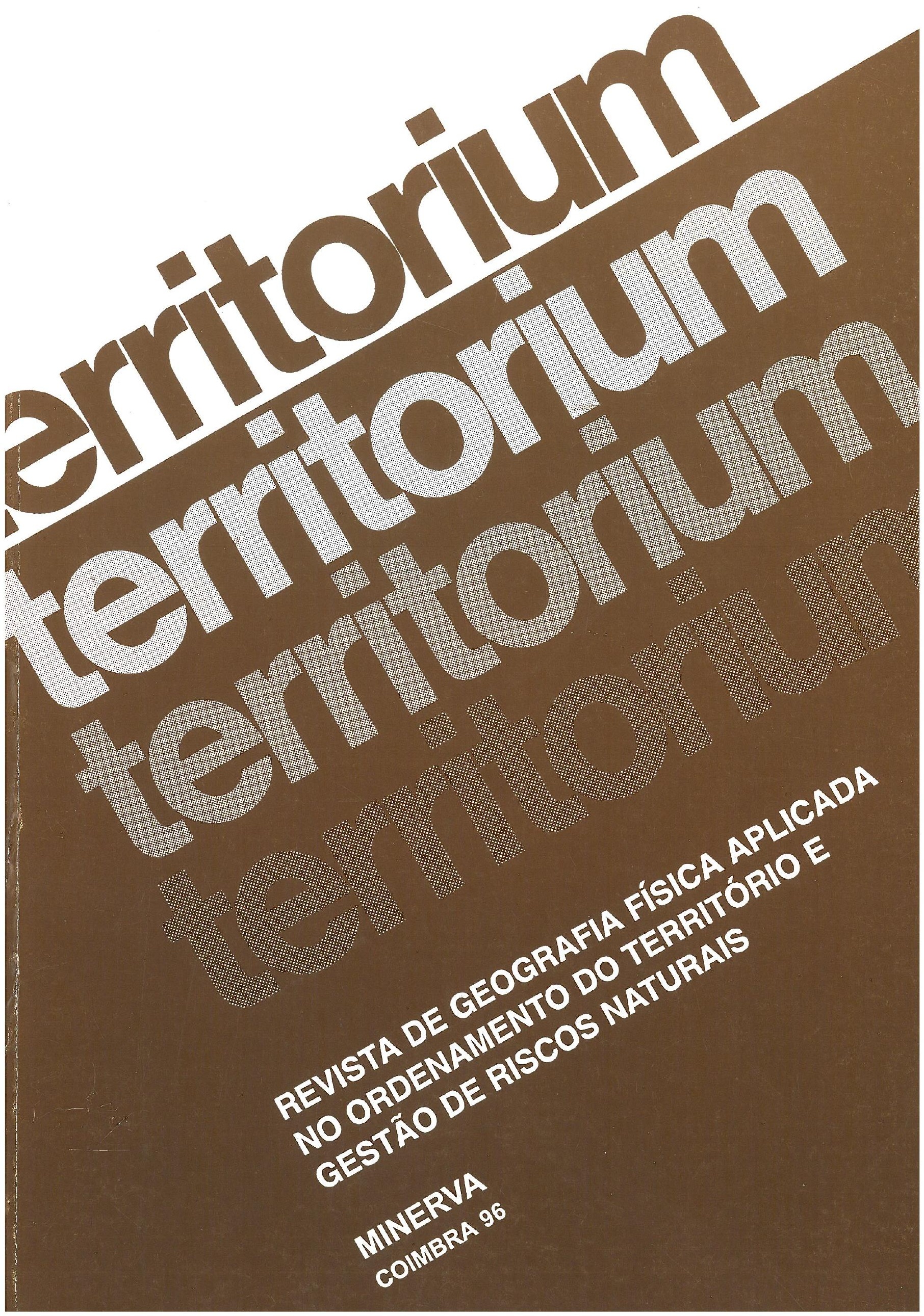




\title{
Florestas e grandes incêndios florestais no mundo
}

\author{
Fernando Rebelo*
}

\begin{abstract}
Resumo:
Desde sempre os geógrafos assinalaram grandes incêndios florestais tanto na zona intertropical como nas zonas frias e temperadas, particularmente nas regiões mediterrâneas. As causas da sua ocorrência poderão ser várias, mas, na maioria dos casos, independentemente do risco climatológico, são os homens os principais responsáveis. Palavras chave:

Florestas, incêndios florestais, riscos.
\end{abstract}

Résumé:

Les géographes ont toujours signalés des incendies de forêt soit à l'intérieur de la zone intertropicale, soit dans les zones froides et tempérées, particulièrement dans les régions méditerranéennes. Les causes des feux pourront être différentes, mais, pour la plupart des cas, et indépendamment du risque climatologique, les hommes sont les responsables majeurs.

Mots clés:

Forêts, incendies de forêt, risques.

\section{Abstract}

Geographers have always refered forest fires in the intertropical zone as well as in the cold and temperate zones, particularly in the mediterranean regions. We can find different causes for the fires, but, independently of climatological risks, man is mainly responsible for them.

Key words

Forests, forest fires, risks.

\section{Introdução}

Para poder estudar as condições climatológicas eventualmente favoráveis à ocorrência e ao desenvolvimento de incêndios florestais, o investigador deverá recorrer, em primeiro lugar, à cartografia das áreas ardidas. Uma grande escala cartográfica, como, por exemplo, a de 1:25000, dar-lhe-á a possibilidade de explorar casos de microclimas mais ou menos favoráveis aos incêndios. Uma pequena escala, como, por exemplo, a de 1:1 000000 , permitir-lhe-á pensar em variedades climáticas regionais de maior ou menor importância para os mesmos. A escala geral ou global, ou seja, a escala do planisfério, levá-lo-á a considerações de carácter zonal.

* Instituto de Estudos Geográficos. Faculdade de Letras. Universidade de Coimbra.
Com efeito, a localização dos grandes fogos florestais a nível mundial autorizará a conclusão de que, consoante o grau de risco climatológico, há zonas onde eles podem ocorrer com mais frequência e zonas onde eles são mais esporádicos, isto é, há zonas potencialmente mais susceptíveis e zonas potencialmente menos susceptíveis de sofrerem com o seu aparecimento.

\section{Os incêndios florestais na zona intertropical}

$\mathrm{Na}$ zona intertropical, os incêndios florestais foram sempre assinalados pelos geógrafos como responsáveis pelo recúo das florestas perante o avanço das savanas. Embora estas possam, muitas vezes, considerar-se climácicas e, portanto, primárias, a verdade é que o fenómeno da savanização, como lhe 
chamava J. DEMANGEOT (1976, p. 68), existe e encontram-se savanas secundárias resultantes de grandes arroteamentos feitos pelo homem.

No caso de pequenos arroteamentos, como os das "bocas" do Orenoco, na Venezuela (idem, ibidem, est. 18), uma vez interrompido o uso agrícola, primeiro aparece a savana e só depois se irá reconstituindo a floresta.

O processo de savanização poderá, todavia, ser praticamente irreversível. A irreversibilidade será tanto mais provável quanto mais longo fôr o tempo do uso agrícola particularmente se baseado em repetidas queimadas. A perda da qualidade do solo levará ao seu abandono pelo homem e a savana instalar-se-á certamente por muitos e muitos anos.

Facilmente incendiáveis durante a época dita seca (época mais fresca e sem chuvas significativas), as florestas tropicais mais sacrificadas têm sido as mesófilas ou mistas, isto é, florestas em que se misturam árvores "sempre verdes" com árvores de folha caduca. Nas florestas mistas, particularmente nas que existem em áreas afectadas por monções, devido à existência de uma massa lenhosa importante e de uma época seca bem definida, a perda de controle de uma queimada, feita em área de clareira com vegetação de savana, pode conduzir a incêndios de grandes proporções, que, com repetição frequente, originarão o avanço da savanização. No entanto, mesmo com uma dominância quase total de árvores Fot. 1 - Queimada em Angola
- proximidades da Quibala
(1969).

\footnotetext{
"sempre verdes", que não ardem facilmente, o homem tem aberto grandes clareiras em florestas de tipo ombrófilo ("rain forest"), não se coibindo mesmo de as regar com petróleo quando se revelaram mais renitentes. P. GOUROU (1966, p. 41), citando um trabalho de P. DEFFONTAINES, refere-se a um caso destes no Brasil dos anos 30 . Factos semelhantes, com petróleo e seus derivados ou mesmo com "napalm", são, hoje, cada vez mais noticiados pelos orgãos de
}

comunicação social a propósito da Amazónia, da Malásia, do Bornéu ou da Nova Guiné, não se sabendo já o que é pior em termos ambientais, se, a longo prazo, o desaparecimento desses pulmões dá humanidade que são as extensas manchas verdes equatoriais, se, no curto prazo, a ocorrência dos grandes incêndios florestais, com a libertação de enormes quantidades de dióxido de carbono responsáveis pelo agravamento do efeito de estufa à superfície do planeta.

Em savanas arbóreas e arbustivas também se podem registar fogos importantes. Em regra, eles começam em queimadas feitas quase no fim da chamada época seca, a pensar numa agricultura sobre cinzas ou a pensar na pastorícia, com o despontar quase imediato de pequenas ervas para o gado (Fot. 1). Quando existem, as florestas relíquia ou mesmo as florestas galeria podem então ser atingidas e serem parcialmente destruidas.

Na maior parte dos casos, sem dúvida, os grandes incêndios da zona intertropical ligam-se à presença do homem, seja por virtude da economia moderna para fazer plantações de árvores consideradas de grande rendimento ou pastagens para criação intensiva de gado, seja por virtude de um modo de vida tradicional em pequenas e médias comunidades.

Em certos casos verificados em regiões tropicais, todavia, as causas podem ser naturais -J. DEMANGEOT

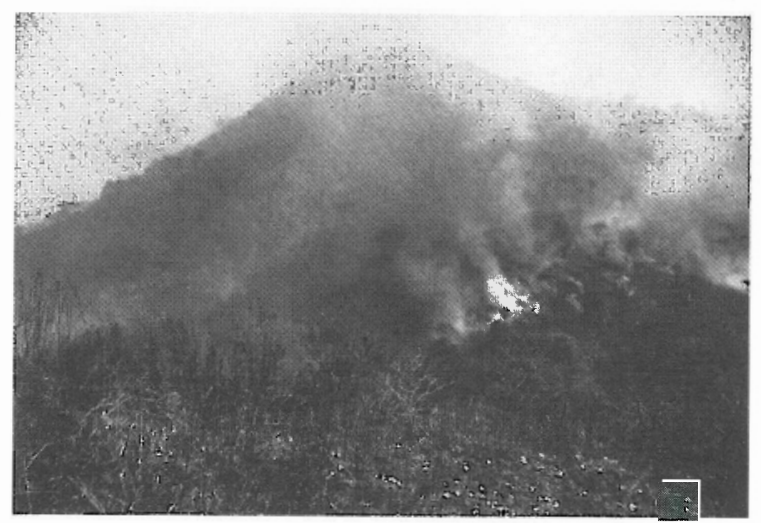

(1976, p. 70) afirma que os incêndios provocados por raios ou por combustão espontânea existem, embora sejam raros. Na verdade, quanto aos primeiros, as longas trovoadas nas frentes de alíseo, verificando-se, portanto, em plena estação não pluviosa, podem provocar faíscas eficazes sobre o capim seco das savanas, que funcionará como autêntico rastilho; outras vezes, as faíscas atingirão espécies arbóreas igualmente secas que irão desencadear fogos. 


\section{Os incêndios florestais da zona fria e do domínio temperado continental da zona temperada}

Em climas frios, com baixas temperaturas médias e abundância de neve durante grande parte do ano, tudo pareceria conjugar-se para que os incêndios florestais não existissem. Não é assim, todavia.

Na Suécia e na Finlândia, com enormes extensões de resinosas, por vezes alternando, outras vezes misturando-se principalmente com bétulas (Fot. 2), tomam-se importantes precauções contra incêndios florestais. E é normal que assim seja, até porque se sabe como, em 1988, arderam cerca de 880000

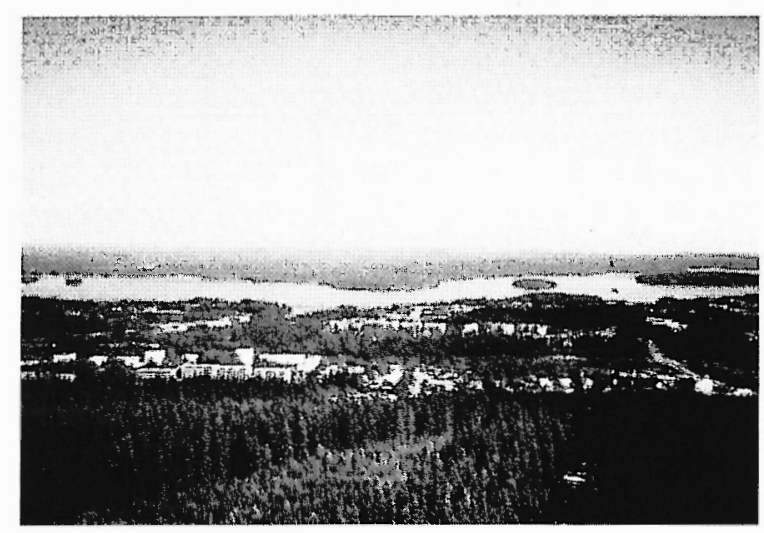

hectares de floresta no Alasca (D. JEFFERY, 1989), apesar do seu clima ser boreal (TREWARTHA e HORN, 1980, mapa extratexto) ou Dfc (subártico continental), segundo a classificação de Koppen-Geiger (A.N.STRAHLER, 1979, mapa extratexto), exactamente como o da maior parte desses dois países.

Com invernos também muito frios, mas com verões mais quentes e, do mesmo modo, com algumas chuvas, em climas temperados continentais, mais ou menos marcados pela altitude, as florestas existem e também sofrem, às vezes, o flagelo dos incêndios.

Ficaram tristemente célebres os grandes incêndios do Verão do mesmo ano de 1988 , originados na sua maior parte pelas trovoadas ocorridas à passagem de frentes frias, quase sem precipitação, culminando meses e meses de grande secura, no Yellowstone National Park (E.U.A.). Este conhecido Parque está situadoem plenas Montanhas Rochosas, numa região com uma altitude média de 2500 metros, mas rodeada por uma extensa área de clima seco (BSk, segundo TREWARTHA e HORN, 1980, p. 297-298 e mapa extratex to) devido à barreira montanhosa concordante que a separa das regiões costeiras do Pacífico, ainda relativamente húmidas à mesma latitude.
No conjunto desse Verão, segundo D. JEFFERY (1989), num total de 49 fogos detectados na área interior e envolvente do Parque, 44 foram atribuidos a faíscas e só 5 a causas humanas. Nestes incêndios, os dados publicados mostram uma devastação de um milhão de acres (cerca de 400000 ha), ou seja, metade da área total do Parque. Embora nesse mesmo ano, devido à enorme seca verificada na América do Norte, o Alasca tenha sido, como vimos, muito mais profundamente abalado pelos fogos, com mais do dobro de devastação ( 880000 ha de floresta), a catástrofe é mais fortemente salientada em Yellowstone por se tratar de um Parque Nacional muito conhecido,

\footnotetext{
Fot, 2 - Floresta na Finlândia - Kuopio (1990).
}

com árvores por vezes tricentenárias, onde quase se ia perdendo a velha Estalagem de Old Faithful e na vizinhança da qual se perderam mesmo 24 edifícios (D. JEFFERY, 1989).

A verdade, porém, é que, mesmo nas regiões onde a humidade de Verão é, em geral, elevada e onde chove com mais frequência ou com mais intensidade do que no resto do ano, podem ocorrer incêndios florestais. Se a floresta existe e o ano se apresenta mais seco do que a média, os incêndios podem aparecer, especialmente quando, na época mais quente, as chuvas se atrasam ou são menos significativas do que habitualmente.

Por isso, países como a Suiça e a Áustria preocupam-se com o ordenamento das suas florestas. Na Suiça, por exemplo, pudemos verificar que se chega ao pormenor de, numa área densamente arborizada e muito procurada pelos turistas (as gargantas do Aar), em avisos escritos em várias línguas, se dizer que é proibido fumar ao ar livre em tempo de "fohen"; com efeito, tratando-se de um vento quente (o chamado "comilão das neves"), quando sopra, aumenta perigosamente o risco meteorológico de incêndio florestal.

Também nos países da Europa Central, há recordações de grandes incêndios florestais. Em 1972, por 
exemplo, o satélite meteorológico ESSA 8 registou extensos incêndios em áreas a Norte de Moscovo, bem como a núvem de fumo com cerca de $2000 \mathrm{~km}$ de extensão que eles criavam - estamos aí no domínio do clima continental com chuvas repartidas por todo o ano, inclusivamente no Verão (Dcb, segundo TREWARTHA e HORN, 1980, p. 297 e mapa extratexto; mais precisamente, Dfb na classificação de Koppen-Geiger, como consta do mapa extratexto de A.N.STRAHLER, 1979).

Com um clima muito semelhante, o Quebec (Canadá) tem tido anos de enormes calamidades, com destaque para 1941, ano em que perdeu 624000 hectares de floresta; não admira, pois, que o Canadá tenha desenvolvido muito as técnicas de prevenção e combate de fogos florestais (P. LANGLEY-DANYSZ, 1991).

Ainda com características climáticas semelhantes, embora com chuvas predominantemente no verão (Dwb, na classificação de Koppen-Geiger, segundo ocitado mapa de A. N. STRAHLER, 1979), o Nordeste da China (Heilungkiang, a Sul do Amur) teve, entre 6 de Maio e 2 de Junho de 1987, o maior dos grandes incêndios florestais assinalados nos últimos tempos, com 870000 hectares de floresta queimada. Daí que também a República Popular da China muito se preocupe com a prevenção dos incêndios florestais (P. LANGLEY-DANYSZ, 1991).

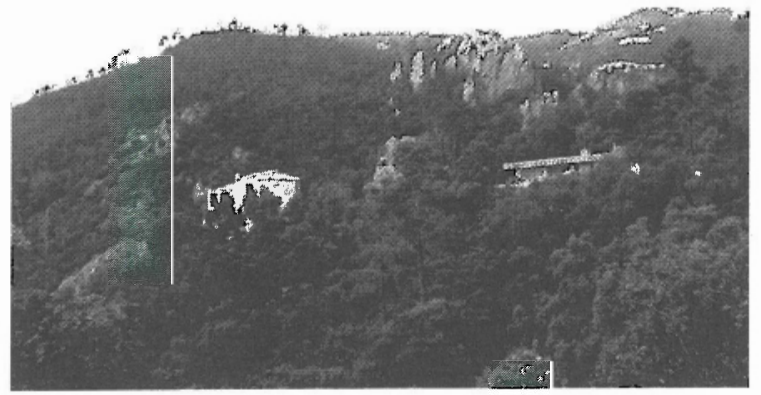

\section{Os incêndios florestais no domínio mediterrâneo}

Ainda na zona temperada, mas em áreas onde o inverno é suave e o verão seco, isto é, nas regiões mediterrâneas, os incêndios florestais assumem características de tragicidade que os fazem mais conhecidos do que os anteriores, apesar de não atingirem tão grandes extensões como alguns deles.
A coincidência do período mais quente do ano com o período mais seco (Csa ou Csb na referida classificação de Koppen-Geiger) cria as condições climaticamente favoráveis, ou seja, oferece um risco climatológico elevado; a eventual existência de grandes manchas de resinosas vem agravar o risco de incêndio florestal.

Por outro lado, a pressão demográfica é, geralmente, maior; por isso, as causas humanas são mais frequentes. Por exemplo, "na Austrália, considera-se que pelo menos $90 \%$ dos fogos de floresta são provocados por imprudências humanas durante as estações de alto risco" (P. LANGLEY-DANYSZ, 1991, p. 934). Também no nosso país, o homem tem sido considerado, directa ou indirectamente, o responsável pela maioria dos fogos; às vezes, todavia, é-o de modo muito, muito indirecto, como no caso das faíscas provocadas pelo vento forte em cabos transportadores de electricidade, o que terá acontecido em dois dos três fogos ocorridos na área de Aljezur em Julho de 1993, o de Alfombras e o de Santa Susana (L. LOURENÇO, A. NUNES e F.REBELO, 1994, p. 55).

A pressão demográfica nas regiões mediterrâneas relaciona-se não só com as causas dos incêndios, mas também com as suas consequências, que além de tudo são mais acompanhadas pelos meios de comunicação social.

Fot. 3 - Maciço do Esterel, dias antes do grande incêndio de 1987.

As áreas ardidas nunca são tão extensas como nos casos acima apresentados. Um grande incêndio florestal como o das Dunas de Mira, Tocha e Quiaios de 19 a 24 de Julho de 1994 estendeu-se por 6802 hectares (L. LOURENÇO, A. NUNES e F. REBELO, 1994); o total de área ardida no pior dos anos de que há registos em Portugal (1991) foi de 161817 ha ardidos (F. MARTINS, 1994). 
Na realidade, mesmo se pensarmos nos dois grandes incêndios florestais que, em Dezembro de $1993 \mathrm{e} \mathrm{em}$ Janeiro de 1994, devastaram extensas áreas arborizadas, respectivamente, da Califórnia e da Austrália, lembramo-nos que ambos foram declarados catástrofes nacionais, não só pela extensão de floresta afectada, mas principalmente pelas casas e outras estruturas construidas que se perderam. Algo de semelhante se passou em Agosto de 1987 no Maciço do Esterel (Fot. 3), na Côte d'Azur (Sul de França) onde as chamas, para além das árvores, destruiram casas e criaram problemas aos turistas que se encontravam nas praias próximas de Cannes.

Em Julho de 1993, nas Dunas de Mira, Tocha e Quiaios, bem como na Serra da Boa Viagem também houve grande devastação. E apesar da área ardida ser muito menor do que nos casos referidos, a palavra catástrofe foi bastante utilizada; no entanto, ela esteve sempre mais presente no incêndio da Serra $(1173,5$ ha) do que no das Dunas, não só pela riqueza florística do Parque Alberto Rei, que acabou por ser quase toda destruida, mas também pela proximidade da cidade da Figueira da Foz, que sofreu os efeitos de espessas nuvens de fumo e a consequente queda de cinzas, mas, principalmente, pela perda de algumas casas, uma das quais um restaurante (L. LOURENÇO, A. NUNES, F.REBELO, 1994).

Pelo clima e pela pressão demográfica, em certos locais agravada com a pressão turística, temos de concordar, então, que, nestas regiões, onde se encontram, por exemplo, Portugal, grande parte da Espanha, da França e da Itália, mas também a Califórnia e a parte sueste da Austrália, a potencialidade de incêndio é grande. Com efeito, o risco climatológico existe e o risco meteorológico pode ser, às vezes, muito elevado. A acção humana torna-se, então, a causa mais frequente de deflagração devendo, portanto, considerar-se como parte integrante do risco de incêndio.

No caso concreto de Portugal, ao contrário do que por vezes se pensa, o clima tem características mediterrâneas. Mesmo nas serras do centro e do noroeste onde, devido à altitude, as chuvas de outono, inverno e primavera são mais abundantes do que no resto do território salientando a influência do Atlântico, no verão não há dúvidas - como escreveu O. RIBEIRO (1986, p. 43), referindo-se ao conjunto do país, "no verão, o clima mediterrâneo reina por toda a parte".

Se uma longa época de chuvas se faz acompanhar de temperaturas que raramente são baixas, as florestas compreendem-se bem. As de carvalho têm vindo a desaparecer desde há alguns séculos dando lugar aos pinhais. Estes, à medida que ardem, vão sendo substituidos, em muitas áreas, por plantações de eucaliptos. Por vezes, pinheiros e eucaliptos misturam-se, ordena- damente ou não. Todos, porém, ficam sujeitos aos condicionalismos de um verão mediterrâneo - dois, três ou mesmo quatro meses de seca. E quando, nesta época, há a conjugação de mais altas temperaturas com mais baixas humidades relativas e fortes ventos de leste, o risco meteorológico atinge os seus valores máximos. Então as nossas florestas ardem e, quase sempre, ardem bem. Muitas vezes, ardem durante vários dias podendo falar-se, embora à nossa escala, de grandes incêndios florestais.

\section{Conclusão}

Claro que, embora potencialmente incendiáveis, muitas das florestas referidas terão poucas probabilidades de arder.

Em primeiro lugar, será, por exemplo, muito difícil ver incendiar-se a floresta ombrófila, a chamada "rain forest" ou "tropical evergreen forest"; a maior parte dos casos corresponderá a áreas restritas e só com muito esforço o homem a fará arder em grandes extensões.

Quanto às outras, a probabilidade maior ou menor de ocorrer um grande incêndio florestal fïcará, em certos casos, dependente do risco climatológico que é a ocorrência de um ano excepcionalmente seco (climas temperados continentais, marítimos ou de transição); noutros casos, quando os totais anuais de precipitação são baixos e ou há uma estação sem chuvas (estação seca) com temperaturas apenas ligeiramente mais baixas do que as da estação das chuvas (climas tropicais contrastados), ou o Verão é sempre quente e seco (climas temperados mediterrâneos), a probabilidade maior ou menor de ocorrência de grandes incêndios ficará, como vimos, muito mais na mão dos homens que, conhecedores das características climatológicas, deverão, em cada momento da época seca, conhecer bem as condições meteorológicas favoráveis (F. REBELO, 1980), ou seja, o risco meteorológico (L. LOURENÇO, 1991). 
territorium 3.1996

\section{BIBLIOGRAFIA}

DEMANGEOT, Jean (1976) - Les Espaces Naturels Tropicaux. Paris, Masson, $190 \mathrm{p}$.

GOUROU, Pierre (1966) - Les Pays Tropicaux. Paris, P.U.F., 4 éd. refondue, $271 \mathrm{p}$.

JEFFERY, David (1989) - "Yellowstone. The great fires of 1988". National Geographic, Washington, 175 (2), p. 255-273.

LANGLEY-DANYSZ, Pernette (1991) - "Un tour du monde des grands incendies". La Recherche, Paris, 234 (Juillet-Aout), p. 932-935.

LOURENÇO, Luciano (1991) - "Uma fórmula expedita para determinar o Indice Meteorológico de risco de eclosão de fogos florestais em Portugal Continental". Cadernos Cientificos sobre Incêndios Florestais, Coimbra, 2, p. 3-63.

LOURENÇO, Luciano, NUNES, Adélia e REBELO, Fernando (1994) - "Os grandes incêndios florestais registados em 1993 na fachada costeira ocidental de Portugal Continental". Territorium, Coimbra, 1, p. 43-61.
MARTINS, Francisco (1994) - "A prevenção como factor primordial na defesa do património florestal". Actas, II EPRIF, Coimbra, 21 a 23 de Fevereiro de 1994, p. 231-237.

REBELO, Fernando (1980) - "Condições de tempo favoráveis à ocorrência de incêndios florestais. Análise de dados referentes a Julho e Agosto de 1975 na área de Coimbra". Biblos, Coimbra, 56, p. 653-673.

RIBEIRO, Orlando (1986) - Portugal, o Mediterrâneo e o Atlântico . Lisboa, Livraria Sá da Costa Editora, 189 p. (4a edição).

STRAHLER, Arthur N. (1979) - Geografia Física. Barcelona, Omega, $767 p$

TREWARTHA, Glenn T.e HORN, Lyle H. (1980) - An Introduction to Clinate. Tokyo, Mc Graw Hill, 5th ed., $416 \mathrm{p}$. 